\title{
Ischemia and inflammation on chronic kidney disease
}

\author{
Nagara Tamaki, MD, PhD ${ }^{\mathrm{a}}$ \\ a Department of Nuclear Medicine, Hokkaido University, Sapporo, Japan
}

Received Apr 24, 2017; accepted Apr 25, 2017

doi:10.1007/s12350-017-0997-6

\section{See related article, pp. 431-440}

Compared with the general population, dialysis patients have a greater incidence of cardiovascular death, mainly due to the high prevalence of either underlying coronary artery disease before starting hemodialysis or cardiovascular risk factors in those with end stage renal disease. ${ }^{1-4}$ Chronic kidney disease (CKD) in general, has a higher incidence of coronary artery disease. The adjusted hazard ratio for death and cardiovascular events increases inversely with estimated glomerular filtration rates (eGFR). ${ }^{5,6}$

While coronary angiography (CAG) and/or coronary $\mathrm{CT}$ angiography has been applied for detecting coronary artery disease (CAD), such procedures have limited value in patients with CKD due to potentially adverse effects of contrast media-induced nephropathy. ${ }^{7}$

Stress myocardial perfusion imaging (MPI) has also been widely used for assessing $\mathrm{CAD}$, particularly for those with CKD without renal deterioration. A number of reports indicated prognostic value of MPI suggested for patients with suspected or extant CAD and those with $\mathrm{CKD}{ }^{8-15}$

The current report is a multicenter prospective cohort study in Japan to determine the ability of MPI to diagnose $\mathrm{CAD}$ and predict the outcomes of patients with CKD who are not definitively diagnosed with CAD (This study). The study aimed to clarify whether MPI can predict cardiac events and determine whether renal dysfunction combined with MPI abnormalities provides additional prognostic information to conventional

Reprint requests: Nagara Tamaki, $\mathrm{MD}, \mathrm{PhD}$, Department of Nuclear Medicine, Hokkaido University, Sapporo, Japan; natamaki@med.hokudai.ac.jp

J Nucl Cardiol 2019;26:441-2.

$1071-3581 / \$ 34.00$

Copyright (C) 2017 American Society of Nuclear Cardiology. markers. Among 529 CKD patients without definitive $\mathrm{CAD}$, a total of 60 cardiac events occurred. The eventfree survival rate was significantly lower for those with kidney dysfunction, higher summed stress score (SSS) on stress MPI, and higher CRP values. Multivariate Cox regression analysis suggested that SSS on stress MPI was an independent predictor with cardiac events in addition to eGFR and CRP in patients with CKD.

This study includes quite an important message, which is, severity of myocardial ischemia on stress myocardial perfusion scan is an independent prognostic indicator in patients with CKD in addition to severity of renal dysfunction and inflammatory parameter. This finding seems to be concordant to the previous findings indicating importance of myocardial ischemia for CKD patient outcome. ${ }^{10-15}$ In other words, CKD patients with severe myocardial ischemia with reduced eGFR with or without elevated CRP are suitable candidates for coronary angiography and subsequent coronary intervention in order to improve their outcome.

Patient selection is quite important for such an outcome study. Most of them are rather old and LVEF is relatively preserved. Therefore, age and/or LVEF were not prognostic indicators. This is somewhat different from many previous prognostic reports using gated perfusion SPECT. ${ }^{8-15}$ In addition, the patient criteria include those with suspected ischemic CAD. It seems to be important to clarify how many of them have symptomatic and unstable conditions, indicating angina at rest or unstable angina. Similarly, those with a long history of CKD often have hypertension and reduced LVEF. Such patients may show poor outcomes. Furthermore, recent guidelines for diagnosing stable CAD suggested that stress MPI may not be an appropriate diagnostic test for those with asymptomatic subjects. ${ }^{16}$ On the other hand, stress MPI might possibly hold an important value for risk analysis even for asymptomatic CKD patients with quite a low eGFR and elevated CRP.

Another concern is the end-point of this study. Of 60 cardiac events, there were only 3 patients with 
cardiac death, 6 with sudden death, and 5 with nonfatal MI. Such relatively good outcome results in this study may come from patient selection which included many asymptomatic subjects. The remaining 46 underwent hospitalization due to heart failure, but there may not be "major" cardiac events, since hospitalization criteria may be different among countries. It would be nice to have a sub-study for predicting really "major" cardiac events by gated MPI.

The current study and many other recent reports indicate importance of stress MPI for predicting future outcomes for those with CKD and/or renal failure. Particularly, the CKD patients showing severe ischemia with systemic inflammation seem to have future cardiac events. Stress myocardial perfusion imaging is a safe and noninvasive test for objective and quantitative assessment of myocardial ischemia. This new and important finding should be confirmed with much more patient data and with more severe cases, hopefully on an international basis.

\section{Disclosure}

Dr. Nagara Tamaki has received research grant from Nihon Medi-Physics Inc, and FujiFilm RI Pharma Inc.

\section{References}

1. Foley RN, Parfrey PS, Sarnak MJ. Epidemiology of cardiovascular disease in chronic renal disease. J Am Soc Nephrol 1998;9(Suppl 12):S16-23.

2. Stack AG, Bloembergen WE. Prevalence and clinical correlates of coronary artery disease among new dialysis patients in the United States: A cross-sectional study. J Am Soc Nephrol 2001;12:151623.

3. Foley RN, Parfrey PS. Cardiac disease in chronic uremia: Clinical outcome and risk factors. Adv Ren Replace Ther 1997;4:234-48.

4. Fung F, Sherrard DJ, Gillen DL, et al. Increased risk for cardiovascular mortality among malnourished end-stage renal disease patients. Am J Kidney Dis 2002;40:307-14.

5. Go AS, Chertow GM, Fan D, McCulloch CE, Hsu CY. Chronic kidney disease and the risk of death, cardio vascular events, and hospitalization. N Engl J Med 2004;351:1296-305.
6. Sarnak MJ, Levey AS, Schoolwerth AC, Coresh J, Culleton B, Hamm LL, et al. Kidney disease as a risk factor for development of cardiovascular diseases: A statement from the American Heart Association Councils on Kidney in cardiovascular Disease, High Blood Pressure Research, Clinical Cardiology, and Epidemiology and Prevention. Circulation 2003;108:2154-69.

7. Majumdar SR, Kjellstrand CM, Tymchak WJ, Hervas-Malo M, Taylor DA, Teo KK. Forced euvolemic diuresis with mannitol and furosemide for prevention of contrast-induced nephropathy in patients with CKD undergoing coronary angiography: A randomized controlled trial. Am J Kidney Dis 2009;54:602-09.

8. Hatta T, Nishimura S, Nakajima T. Prognostic risk stratification of myocardial ischaemia evaluated by gated myocardial perfusion SPECT in patients with chronic kidney disease. Eur J Nucl Mol Imaging 2009;36:1835-41.

9. Nakajima K, Nishimura T. Inter-institution preference-based variability of ejection fraction and volumes using quantitative gated SPECT with 99mTc-tetrofosmin: A multicentre study involving 106 hospitals. Eur J Nucl Med Mol Imaging 2006;33:127-33.

10. Momose M, Babazono T, Kondo C, Kobayashi H, Nakajima T, Kusakabe K. Prognostic significance of stress myocardial ECGgated perfusion imaging in asymptomatic patients with diabetic chronic kidney disease on initiation of haemodialysis. Eur J Nucl Mol Imaging 2009;36:1315-21.

11. Hase H, Joki N, Ishikawa H, Fukuda H, Imamura $Y$, Saijyo $T$, et al. Prognostic value of stress myocardial perfusion imaging using adenosine triphosphate at the beginning of haemodialysis treatment in patients with end-stage renal disease. Nephrol Dial Transplant 2004;19:1161-67.

12. Hakeem A, Bhatti S, Dille KS, Cook JR, Samad Z, Roth-Cline $\mathrm{MD}$, et al. Predictive value of myocardial perfusion single-photon emission computed tomography and the impact of renal function on cardiac death. Circulation 2008;118:2540-49.

13. Nakajima $\mathrm{K}$, Matsuo S, Okuyama $\mathrm{C}$, Hatta $\mathrm{T}$, Tsukamoto $\mathrm{K}$, Nishimura $\mathrm{S}$, et al. Cardiac event risk in Japanese subjects estimated using gated myocardial perfusion imaging, in conjunction with diabetes mellitus and chronic kidney disease. Circ J 2012;76:168-75.

14. Doukky R, Fughhi I, Campagnoli T, Wassouf M, Ali A. The prognostic value of regadenoson SPECT myocardial perfusion imaging in patients with end-stage renal disease. J Nucl Cardiol 2017;24:112-18.

15. Bhatti S, Hakeem A, Dhanalakota S, Palani G, Husain Z, Jacobsen G, Ananthasubramaniam K. Prognostic value of regadenoson myocardial single-photon emission computed tomography in patients with different degrees of renal dysfunction. Eur Heart $\mathbf{J}$ Cardiovasc Imaging 2014;15:933-40.

16. ACCF/AHA/ACP/AATS/PCNA/SCAI/STS Guideline for the Diagnosis and Management of Patients With Stable Ischemic Heart Disease Circulation 2012;126:e354-e471. 